\title{
The frontier in Cardiac Surgery is intellectual
}

\author{
Carlos A. Mestres' ${ }^{1}$, Alberto Pozzoli', Maurizio Taramasso', Michel Zuber ${ }^{1}$, Francesco Maisano ${ }^{1}$ \\ 'Department of Cardiac Surgery, University Hospital Zürich, Zürich CH-8091, Switzerland. \\ ${ }^{2}$ Department of Cardiology, University Hospital Zürich, Zürich CH-8091, Switzerland.
}

Correspondence to: Dr. Carlos A. Mestres, Department of Cardiac Surgery, University Hospital Zürich, Rämistrasse 100, Zürich CH-8091, Switzerland. E-mail: carlos.mestres@usz.ch

How to cite this article: Mestres CA, Pozzoli A, Taramasso M, Zuber M, Maisano F. The frontier in Cardiac Surgery is intellectual. Vessel Plus 2019;3:38. http://dx.doi.org/10.20517/2574-1209.2019.20

Received: 4 Jul 2019 First Decision: 5 Aug 2019 Revised: 6 Aug 2019 Accepted: 8 Aug 2019 Published: 18 Nov 2019

Science Editor: Mario F. L. Gaudino Copy Editor: Cai-Hong Wang Production Editor: Tian Zhang

\begin{abstract}
Cardiac Surgery is a Specialty undergoing profound changes. Since its inception, innovation has been at the forefront of activities seeking for the best of the patients. The introduction of the heart-lung machine in clinical practice in the 1950s of the twentieth century allowed for the correction of intra- and extracardiac defects. The recent past two decades have seen the progressive incorporation of transcatheter therapies to treat a variety of heart defects. Multimodality imaging approach has become a fundamental tool in the pre- intra- and postoperative assessment of patients. The future in Cardiac Surgery contemplates redesigning training programs with the mandatory acquisition of catheter skills, the knowledge of the different imaging modalities and allocation of resources and timing for basic and translational research.
\end{abstract}

Keywords: Cardiac Surgery, innovation, frontier, intellectual component, transcatheter therapies, multimodality imaging

\section{INTRODUCTION}

Cardiac Surgery is a well-established, mature, surgical specialty. It has been considered a young specialty as in the way we practice, the first reported cases of major cardiac operations are dated back in 1953 when John Gibbon from Philadelphia first performed the intracardiac correction of an atrial septal defect using the heart-lung machine (HLM $)^{[1,2]}$. The classical historical vignette of Ludwig Rehn repairing a stab wound of the heart in $1896^{[3]}$ is generally considered as the pioneering surgical event which cleared the path towards a more advanced approach to the surgical treatment of cardiac diseases. After four decades of laboratory research, it became clear that the correction of intracardiac defects could be possible in the middle of the 20 th century. The courageous attempts of Gibbon ${ }^{[1]}$ with the HLM, Lillehei ${ }^{[4]}$ with cross-

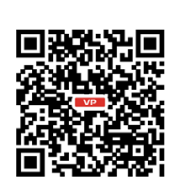


circulation and DeWall ${ }^{[5]}$ in the beginning of the fifties of the twentieth century have to be seen with the perspective of time as ground-breaking events that could probably be difficult to replicate in current times.

Cardiac Surgery has undergone impactful changes since it became a medical specialty. It has been associated with the development of specialties within the chest and related to the cardiovascular surgery. The name has also undergone changes and different terms have been used over time. Cardiac Surgery, cardiovascular surgery, cardiothoracic surgery, have been associated to innovation. The approach chosen by Gibbon $^{[1]}$ was innovative at that time. The idea of oxygenating the blood while circulating through artificial tubes out of the body was an outstanding example of innovation. This followed the original studies of Max von Frey at the Carl Ludwig Leipzig Physiological Institute at the end of the $1890 \mathrm{~s}^{[6]}$, who also innovated at that time by developing a system for blood oxygenation. Since its inception as an independent specialty, inclusive of name changing, Cardiac Surgery has also been associated to education. Education is the foundation of the individual and the society. Education in Cardiac Surgery is a dynamic process and is considered as one of the most important activities in the Specialty. This has been highlighted over the years by many. Every department, every scientific society allocates resources and budget to cope with the needs of those who will deliver high-quality services and is highlighted in their respective mottos ${ }^{[7,8]}$.

As time goes by, it is evident that our Specialty changes. What it was done in the early developmental phases, does not apply in current times. The introduction of the HLM represented a breakthrough in surgery as it allowed to repair or palliate a number of previously unaddressed pathologies. Over the past 70 years, we witnessed the evolution of the techniques, the consolidation of the specialty, the improvement in clinical results, thus resulting in the benefit of the community. This has been extensively recorded in the literature $^{[9-13]}$.

There have been substantial changes over time in the perception and action in the Specialty. Coronary artery surgery continues to be the gold standard in the treatment of triple-vessel disease, with or without left main lesions ${ }^{[14]}$. Despite the advent of the newer transcatheter techniques that are later discussed, mitral valve repair for degenerative disease ${ }^{[15]}$, surgery for infective endocarditis ${ }^{[16]}$, aortic valve repair ${ }^{[17]}$, obstructive cardiomyopathy ${ }^{[18]}$ and aortic surgery ${ }^{[19]}$, to name just a few, are well-established and routine procedures all over. On the contrary, cardiac pacing, a surgical activity for decades ${ }^{[20]}$, including all sorts of pacemakers and implantable cardioverter defibrillators ${ }^{[21]}$ was slowly taken over by cardiologists almost everywhere. The improvement and miniaturization of hardware, the easiness of implantation and other factors, progressively shifted pacing towards Cardiology.

Cardiac Surgery currently faces new challenges. This is well known, as challenges are always out there and are the foundation for development. This means Cardiac Surgery is continuously evolving as the surgeons do. It is not to be forgotten that surgery, despite its etymology, is not a manual activity, it is an intellectual

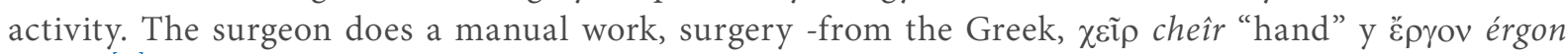
"work" ${ }^{\text {"[2] }}$, which is intellectually driven. Here we tried to understand which are the current challenges in Cardiac Surgery, where the frontiers for future development are and what we need to do to overcome difficulties in an adaptive process.

\section{THE CHALLENGES AND THE FRONTIER}

Adaptive changes result from challenges. Darwin understood that species undergo adaptive changes as a response to environmental challenges ${ }^{[23]}$, a theory that has also been challenged. The technological breakthrough of the HLM was challenged by a number of technological and biological umprecedented problems related to the new interactions between machines and the human body. New materials and new technology resulted in sophisticated devices incorporating better pump heads, biocompatible surfaces for cardiopulmonary bypass tubing aiming at reducing inflammatory response $e^{[24]}$, multiple in-line sensors for 
better safety, more effective and less traumatic oxygenators with superior performance ${ }^{[25]}$, in-line filters of all kinds ${ }^{[2,27]}$, hemoadsorbers ${ }^{[28]}$ and other complements that allowed safer conduct of cardiopulmonary bypass for repair of cardiac disease.

The challenges in Cardiac Surgery are like the nine-headed Hydra ${ }^{[29]}$. As highlighted by De Paulis ${ }^{[30]}$, new technologies, professional issues, educational differences, the changing profile of the cardiac patient, the increased complexity, the trend towards reducing the surgical access and the booming of transcatheter techniques and technologies over the past couple of decades, have designed a complex scenario that can only be addressed with imagination and adaptive willingness.

Where does the Frontier lie? Although individual opinions can be challenged by many, the frontier is related to our understanding of what we used to neglect.

\section{IMAGING}

Imaging has evolved in the years from a diagnostic tool to an alternative to direct vision; today imaging is critical in all phases of patient handling: from diagnosis, to stratification, indication, planning, intraprocedural guidance and follow-up. Intraprocedural imaging is the eye of the modern surgeon for guidance of endovascular procedures.

\section{The impact of conventional imaging}

The developments in imaging over the past three decades have substantially modified our approach to the disease and the patient. What currently are conventional plain X-rays were impactful over hundred years ago as radiology allowed the physicians to see things that no one could imagine ${ }^{[31]}$. Diagnosis improved, accuracy allowed for better delivery of care. Arteriography ${ }^{[32,33]}$ allowed surgeons to identify and understand the anatomy of lesions amenable for surgical therapy. And this applied to each and every vessel in the body.

\section{The ultrasound - echocardiography - quality}

In the field of Cardiology and Cardiac Surgery, echocardiography developed in a way that it currently plays the same role EKG used to play for decades, namely a foundational examination to support a clinical diagnosis. The introduction of M-mode echocardiography in 1954 by Edler and Hertz ${ }^{[34]}$ represented a breakthrough in diagnosis in Cardiology. Later, two-dimensional echocardiography improved the ability to make the interpretation of cardiac valvular anatomy for better characterization of structural competence. The introduction of the Doppler effect in echocardiography, by Hatle ${ }^{[35,36]}$ paved the way for echocardiography to become the major diagnostic tool in future Cardiology and Cardiac Surgery. Further refinements like transesophageal echocardiography in $1976^{[37]}$ and more recently the $3 \mathrm{D}$-echocardiography ${ }^{[38]}$ anatomical description have confirmed the critical role of echocardiography in the assessment of valve disease and cardiac function. Even 3D echocardiography has eveloved in rapid steps to full volume with best frame rate without and even with color Doppler sonography. Computer progress made it possible that we can see double volumes from the same data set, visualizing the mitral valve from the left atrial side and from the left ventricle side at the same time, without stich artifacts. Machine learning is helpful for performing anatomical models from the $3 \mathrm{D}$ data set and do multiple measurements by itself with a fantastic reproducibility.

Echocardiography has also played a significant role in improving the quality of Cardiac Surgery. Surgeons and cardologists have improved their standards by incorporating echocardiography in their practices. Unfortunately, it took long for surgeons to adopt this tool as part of the daily activities. Surgeons understood the value of echocardiography, however, little was done for long time to include it in the training programmes. As echocardiography is not only a preoperative diagnostic tool but also a critical 


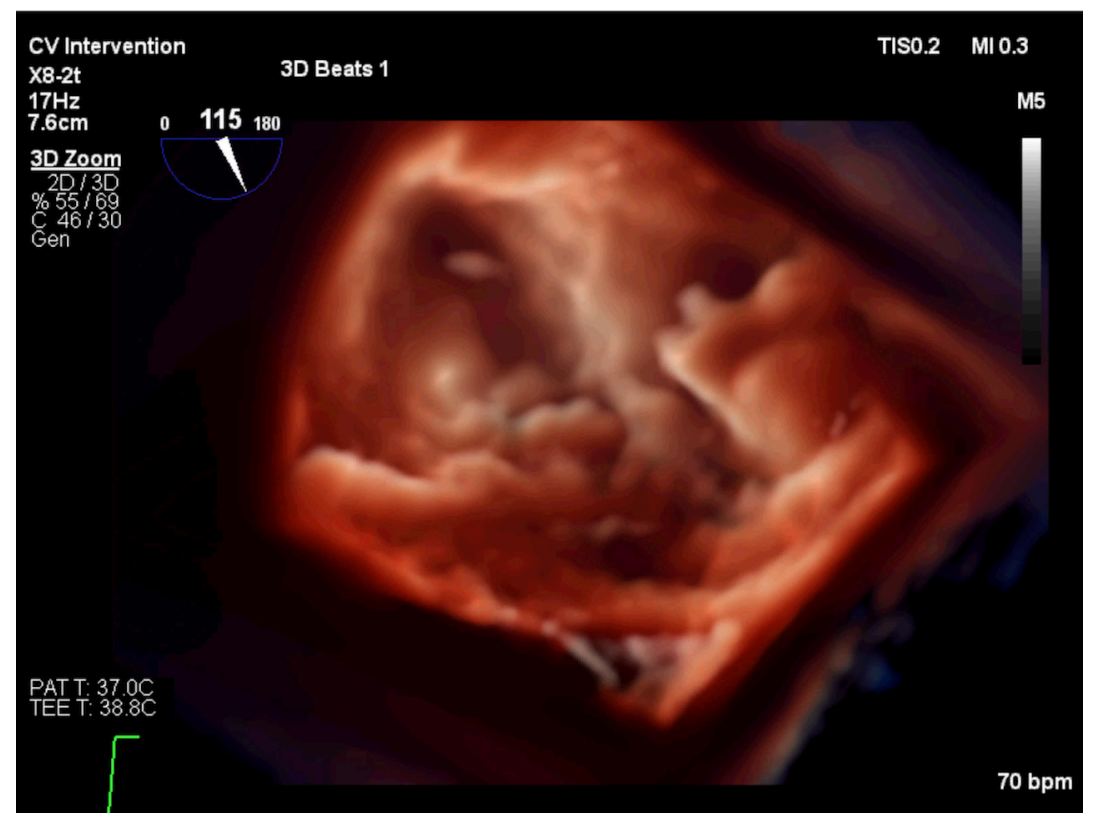

Figure 1. Preoperative image of mitral P3 segment flail in postrheumatic valve

part of the intra- and postoperative anatomical and functional assessment ${ }^{[39]}$ and even as important a quality assurance instrumentation, its role in education must be reinforced. The ability to simulate interventions with computer technology pushed preoperative planning in a "sine qua non" position and will revolutionize a lot of future interventions, too. So, young surgeons need to become familiar with all such technologies not to miss future requirement before interventions. Implementation of computer technology and sophisticated postprocessing as for example true view and changes of light sources in the picture, will bring even more realistic anatomy to the treating physicians [Figures 1-3].

\section{Advanced radiology}

Computed tomography (CT) and magnetic resonance imaging (MRI) imaging changed the medical world as they allowed for a multiple view of the anatomy, for the identification of infracentimetric lesions, for better tissue characterization and the analysis of structural motion ${ }^{[40,41]}$. These examinations are currently a fundamental part of medical practice and physicians frequently rely on them than on their own clinical judgment to design a pathway for therapy. Indeed, dramatic changes have already occurred in this field, including the introduction of promising new technologies such as coronary CT angiography ${ }^{[42]}$ and substantial reductions in reimbursement driven by cost-cutting and concerns regarding overuse. New technologies such as coronary fluid dynamics and physiology derived from $\mathrm{CT}^{[43]}$ and emission tomography ${ }^{[44]}$, offer the hope that we will soon gain outstanding and reliable imaging in coronary artery disease diagnosis: both anatomic and functional information will be obtained non invasively.

\section{Multimodality and fusion imaging technologies}

We live in an era of innovation and technological evolution, which is expressed at its best in the cardiovascular field. As already discussed, change and evolution are unstoppable. This inevitably influences the choices and future directions of a highly specialized discipline such as cardiac surgery. The advent of transcatheter technologies has progressively become a part of the armamentarium of available treatments, surely in a complementary way, merging with classical cardiac surgery and stimulating it for continuous improvement and refinement. The main advantage of percutaneous therapies is reducing the access and the invasiveness of the procedure, operating on the beating heart in patients at high surgical risk, avoiding 


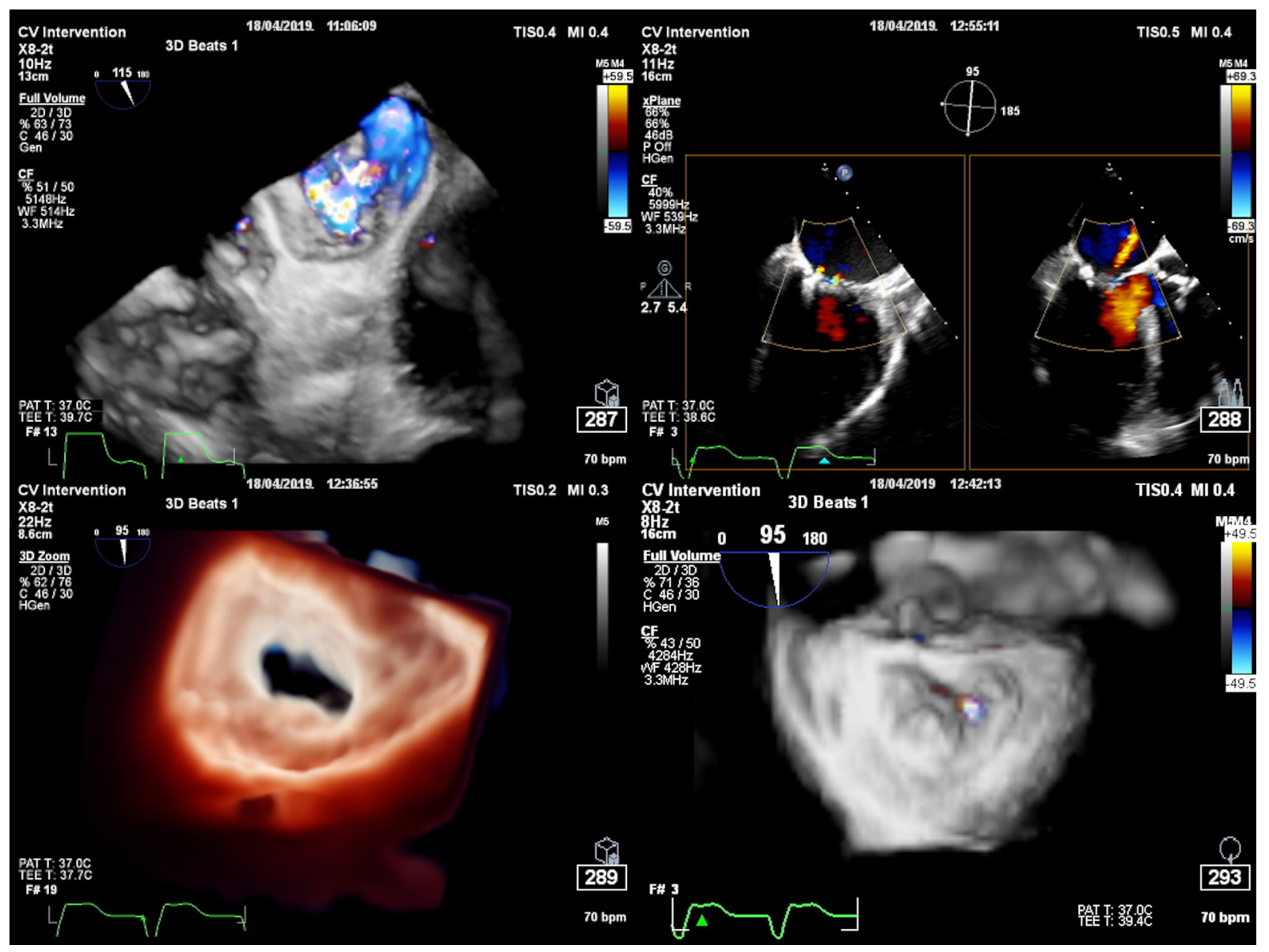

Figure 2. The same P3 lesion undergoing MitraClip ${ }^{T M}$ procedure (left upper: severe MR before, right upper minimal MR after clipping, left lower diastolic frame in surgical view after clipping, medial commissure and right lower with minimal MR besides medial commissure in systolic view)

the burden of the extracorporeal circulation. This translates into new needs and new demands, in addition to the knowledge of transcatheter therapies, equipment and acquisition of wire skills. It then becomes mandatory to acquire knowledge of cardiovascular imaging, for the planning of procedures and for the guidance during interventions (intraprocedural imaging).

One of the most stimulating and enriching steps for future generations of cardiac surgeons will be the incorporation of imaging techniques in the surgical curriculum, the knowledge of the peculiarities of each image modality and how to proceed on a daily basis in clinical practice. One practical example could be understanding and navigating the right heart anatomy, using only the information provided by fluoroscopy, to guide interventional tricuspid procedures ${ }^{[45]}$ [Figure 4].

The idea that the field of multimodality imaging is far from the surgical domain and it is the exclusive competence of other professional figures of the heart team, such as the cardiologist echocardiographist, the interventional cardiologist (intraprocedural imaging and its modalities) or the radiologist (e.g., computerized tomography and cardiac magnetic resonance) is, unfortunately, well acknowlegded. This way of thinking is restricting and risks confining the figure of the cardiac surgeon to that of the final recipient, a passive user, a handworker. The risk is to become insensitive to technological evolutions and new skills that could be acquired. Due to the technological refinement, cardiac CT is a routine part of assessment in transcatheter therapies ${ }^{[46]}$. The sequential incorporation of increasingly sophisticated software has 


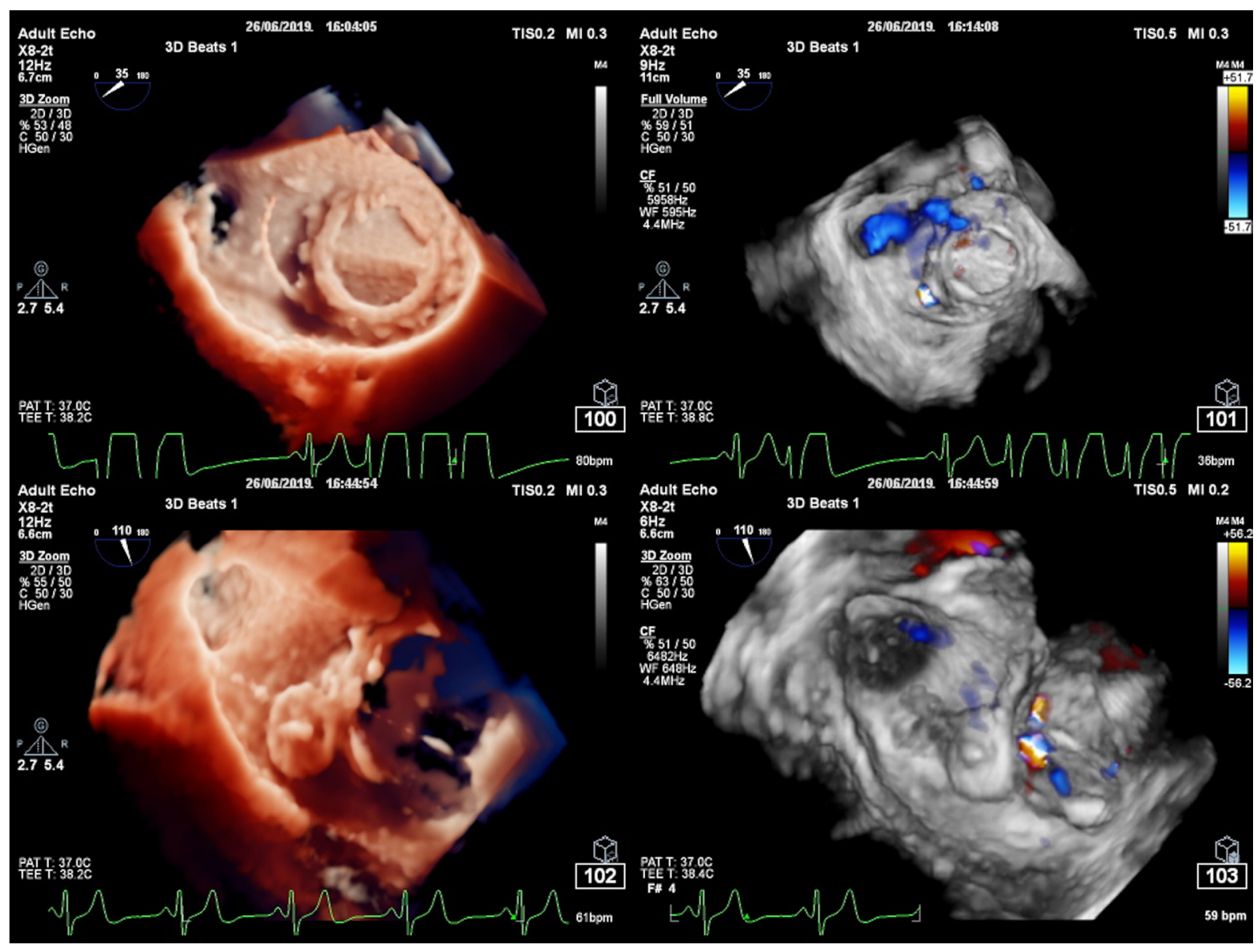

Figure 3. Picture of paravalvular leak (PVL) closure of a mechanical bileaflet $O n-X$ valve at 0800 with vascular plug amplatzer device. Left upper panel shows placement of the guidewire in the PVL, right upper the PVL at 0800 in systolic surgical view. Left lower end panel of procedure with amplatzer device in PVL and right lower no PVL left in color Doppler 3D systolic frame

allowed for pre-procedural planning resulting in near perfection at the time of device implantation. Learning to analyze a cardiac CT scan, measuring the size of the valve rings, the areas, the distance of the coronary arteries from the annulus, are skills acquired with great speed and precision by those who see and understand the cardiac structures with their own eyes in the daily practice. Surgical assessment of anatomical imaging prior to the procedures has become standard in most active centers and it is a mandatory step to achieve safety and effectiveness.

Especially to face complex interventional procedures, integrating in a multimodal way echocardiographic information and CT, fusioning echocardiographic and angiographic intraprocedural images with last generation softwares - or CT and fluoroscopy [Figures 5 and 6] - should become part of the cultural background of future cardiac surgeons ${ }^{[47]}$. Good surgeons of the future will be independent in the correct reading of the patient's imaging just like today they are good in interpreting the anatomy by direct vision: the one is not excluding the other... it is augmented reality, fusion of multimodality imaging inputs to enrich the information and achieve better results.

The progressive technological evolution has led the world of cardiac imaging to technical improvements considered unexpected only a few years ago. In a few years, there has been a move from two-dimensional diagnostic imaging, very operator-dependent, to the current highly sophisticated and integrative multimodality imaging approach ${ }^{[48]}$. This is certainly a great innovation and the next frontier for those who 

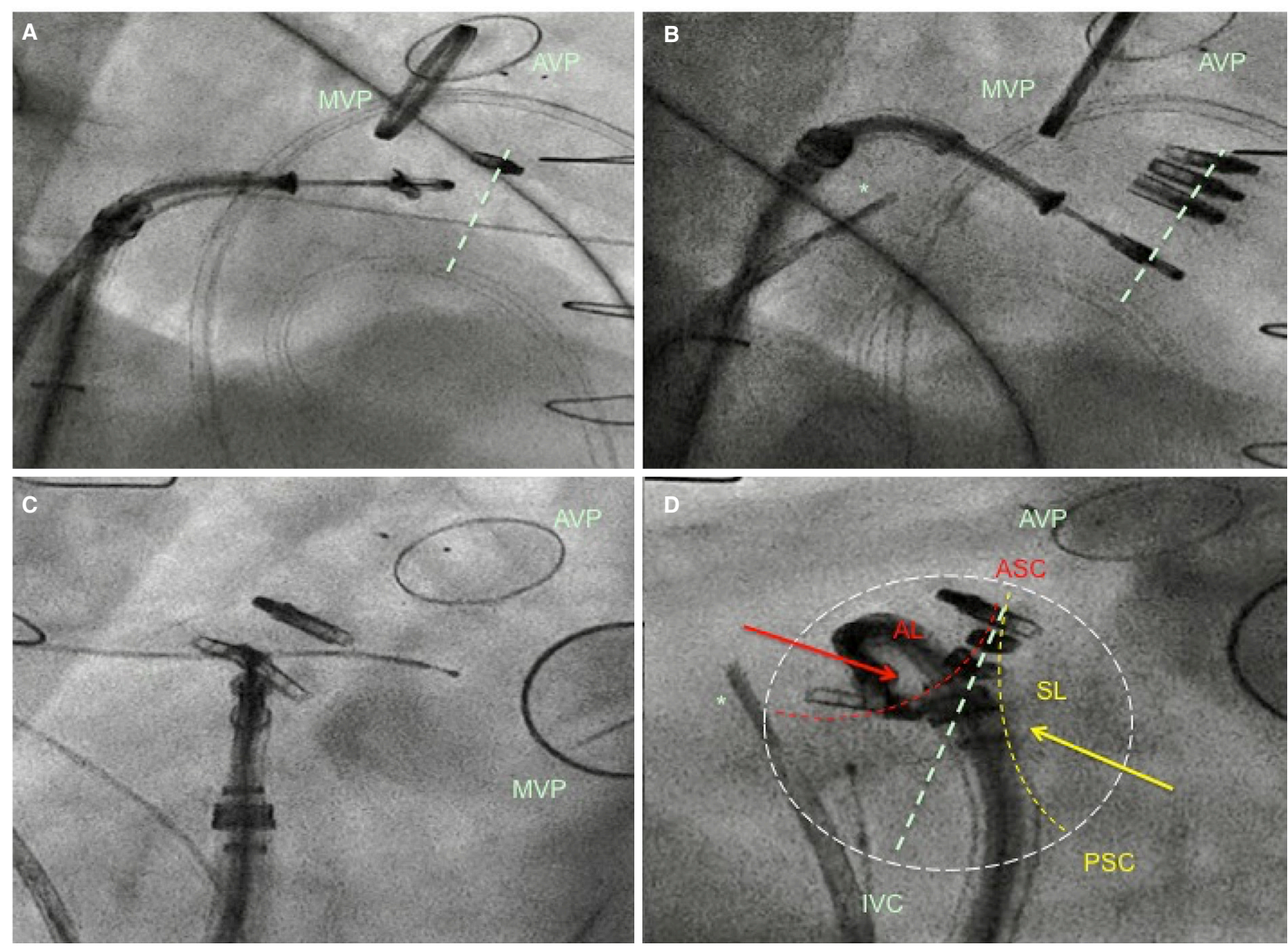

Figure 4. $A$ and $B$ : show two right fluoroscopic 2-chamber views during percutaneous tricuspid MitraClip ${ }^{\text {TM }}$ procedure, useful to advance the catheters towards the tricuspid valve and to calculate the trajectories to address the targeted commissure. Light green dotted line traced in Panel A-B is the hypothetical line of coaptation between the anterior and the septal leaflet; C and D: show two enface fluoro views during the same procedure, useful to guide catheter navigation within the valve area and to position the MitraClip ${ }^{\mathrm{TM}}$ in the anteroseptal commissure (ASC), closest to the tricuspid annulus. AL is anterior leaflet (dotted line); PSC (yellow) posteroseptal commissure with SL septal leaflet (dotted line). Light green dotted line traced in Panel D is the line joining the aortic valve (ASC) and the inferior vena cava, reflecting the theoretical line of coaptation between the anterior and the septal leaflet. Arrows indicate traction forces on the leaflets done by the edge-to-edge percutaneous repair. The white dotted circle depicts the theoretical tricuspid ring. ${ }^{*}$ Intracardiac echocardiography (reprinted with permission from Pozzoli et al. ${ }^{[47]}$ ). AVP: aortic valve prosthesis; MVP: mitral valve prosthesis

want to deal with cardiovascular therapies. Surgeons should more actively participate in this assessment and being able to further increasing their navigation skills.

\section{THE CHANGING SCENARIO}

\section{Understanding the evolution}

The advent of transcatheter/endovascular techniques has represented the latest major breakthrough in Cardiology, Cardiac and Vascular Surgery. From the first reported case of transcatheter aortic valve implantation in 2002 by Cribier et al. ${ }^{[49]}$, there has been an unstoppable development in the treatment of valvular disease. The role of surgery in the treatment of the so-called structural heart disease although popular a still somewhat confusing term ${ }^{[50]}$ - is currently challenged by the community as more information is collected that supports the modification of the level of evidence for a given therapy ${ }^{[51]}$. One may argue that a large part of the evidence accumulated over the past couple of decades, not only in the field of structural heart disease, develops from sponsor-initiated studies and therefore there may be or there actually are a number of flaws and biases for obvious economic interests. On the other hand, investigatorinitiated trials are less frequently produced as there are issues with regulatory bodies and financial support. 


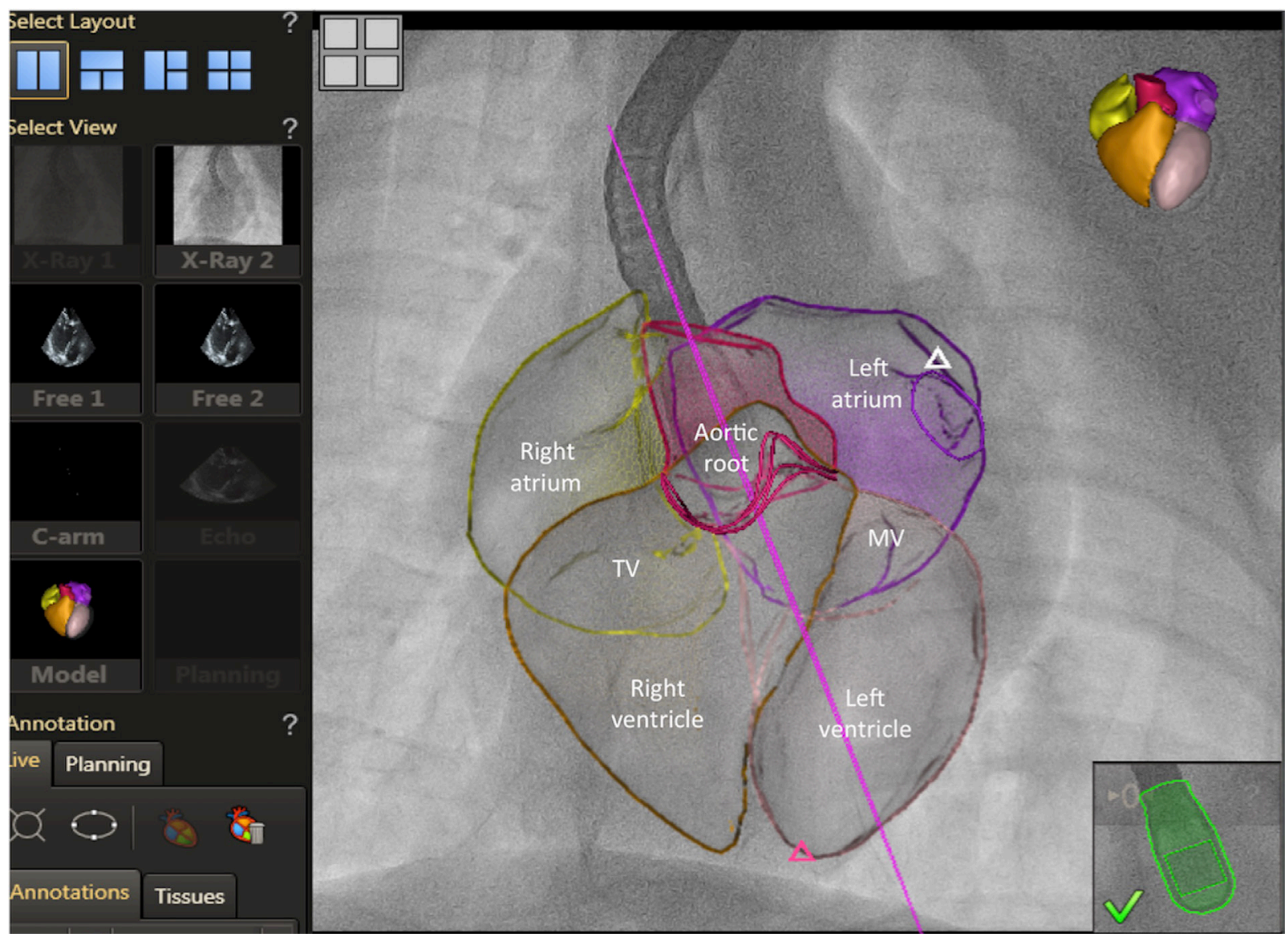

Figure 5. Echo/fluoro overlay of segmented 3D heart in fluoro space. TV: tricuspid valve; MV: mitral valve

Even with public funding, investigators may face problems with logistics and regulations that are a burden for someone with suboptimal structure for execution of reserch projects. The European Union regulations on research ${ }^{[52]}$ are an example of how complex and challenging the scenario becomes.

Transcatheter therapies came to stay and conventional surgery had to sustain the impact of this growing and currently accepted approach to treat heart and vascular disease. There has been a paradigm shift in therapeutic strategies; again, the example of transcatheter aortic valve implantation ${ }^{[51]}$ and transcatheter repair of mitral insufficiency ${ }^{[53]}$ shows that adaptive change is required and surgery and the surgeons must complete the initial efforts towards a full adoption of these technologies.

The same phenomenon has been observed in the field of Vascular Surgery. Once a fully open surgical specialty, vascular surgeons converted the Specialty in a combined surgical activity, for which wire skills became the routine. Thus, conventional surgery and transcatheter procedures are mixed and no differentiation within the team is made.

\section{The intellectual component}

From all of the above one can infer that challenges are to be positively accepted. Form follows function ${ }^{[54]}$ and this is why nature defined the evolution of species, as species undergo adaptive changes ${ }^{[55]}$. A quick look into different species heart morphology allows to understand why the heart has different forms and sizes $^{[56]}$. 


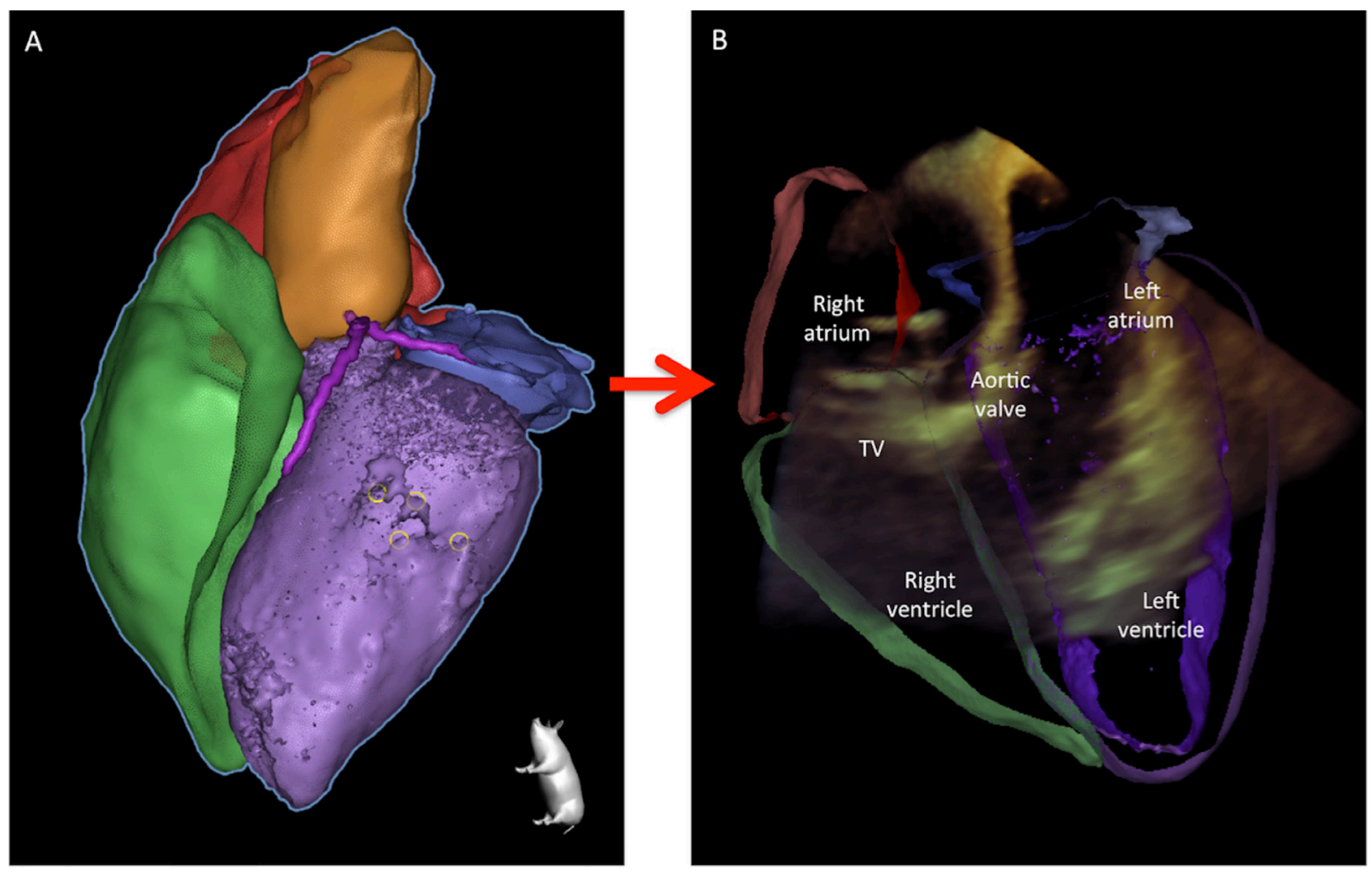

Figure 6. A glimpse into the future. Initial validation step of CT vs. Echo segmentation merged together in one image. TV: tricuspid valve

The key point is not to make the interpretation of information derived from clinical trials, or to learn how to work with a modern state-of-the-art technology or simply to perform a given procedure with success. Embracing technologies, analyzing data, acquiring hands-on proficiency in something are important in the daily medical practice. However, the most important is the intellectual changes required to understand a rapidly changing scenario and how to adapt to a fast-moving world that entails professional new opportunities.

The intellect is a unique characteristic of the human being. The intellect is the faculty of reasoning and understanding objectively, especially with regard to abstract matters ${ }^{[57]}$. As it is supposed to be the most advanced in comparison with the remaining of the living species, it makes sense to understand that challenges in Cardiac Surgery do have a critical intellectual component.

\section{THE FRONTIER}

A frontier is defined as the extreme limit of understanding or achievement in a particular area ${ }^{[58]}$. Therefore, this definition entails a substantial intellectual component. What seems clear is that all is about our understanding of the problem. The current scenario is that of technological evolution, combined with changing patterns in patient and environmental complexity, the availability of techniques allowing for a reduced access for treatment of structural heart diseases and changes in therapeutic paradigms through the collection of evidence.

The frontier is the ability to update our knowledge and skills and to implement responses that will allow to redesign and reorganize the surgical practice by expanding the surgical portfolio. 


\section{THE FUTURE}

The future in Cardiac Surgery must contemplate impactful changes to allow the surgeon to continue its regular high-quality practice in cardiovascular disease. A number of issues to consider in this, already here, future can be summarized as follows:

1. Modification of the training process

(1) Redesign of curriculum and syllabus;

(2) Training in cardiovascular imaging;

(3) Structured training in coronary angiography and interventional procedures;

(4) Acquisition of specific skills for catheter-based interventions;

(5) Mandatory simulation training;

2. Support innovation

(1) Allocate departmental resources to enhance pooling of ideas;

(2) Support departmental/institutional basic and clinical research (back to the basis);

(3) Mandatory training in the animal laboratory;

\section{CONCLUSION}

Cardiac Surgery is a Specialty in continuous evolution. Since the introduction of the HLM, which allowed for the correction of intracardiac and extracardiac defects of all kinds, significant changes have been introduced in the surgical practice.

The current scenario, with the consolidation of transcatheter therapies in the treatment of structural heart disease, represents a challenge to conventional surgical practice. The evolution of Cardiac Surgery must include a redesign of the training of current and future specialist and a transformation of the daily practice. Conventional surgery and transcatheter procedures are to be routinely scheduled with no differentiation within the surgical team.

This needs an adaptive change, with an intellectual transformation to understand the importance of incorporating a different type of training and practice.

\section{DECLARATIONS}

\section{Authors' contributions}

Researched data for the article, discussed its content, and wrote, reviewed, and edited the manuscript: Mestres CA

Researched data for the article, and wrote, reviewed, and edited the manuscript: Pozzoli A

Discussed the content and reviewed and edited the manuscript before submission: Taramasso M, Zuber M, Maisano F

\section{Availability of data and materials}

Not applicable.

\section{Financial support and sponsorship}

None.

\section{Conflicts of interest}

All authors declared that there are no conflicts of interest. 


\section{Ethical approval and consent to participate}

Not applicable.

\section{Consent for publication}

Not applicable.

\section{Copyright}

(c) The Author(s) 2019.

\section{REFERENCES}

1. Miller BJ, Gibbon JH, Fineberg C. An improved mechanical heart and lung apparatus; its use during open cardiotomy in experimental animals. Med Clin North Am 1953;1:1603-24.

2. Gibbon JH Jr. Application of a mechanical heart and lung apparatus to cardiac surgery. Minn Med 1954;37:171-85.

3. Blatchford JW 3rd. Ludwig Rehn: the first successful cardiorrhaphy. Ann Thorac Surg 1985;39:492-5.

4. Lillehei CW, Cohen M, Warden HE, Varco RL. The direct-vision intracardiac correction of congenital anomalies by controlled cross circulation; results in thirty-two patients with ventricular septal defects, tetralogy of Fallot, and atrioventricularis communis defects. Surgery 1955;38:11-29.

5. DeWall RA, Gott VL, Lillehei CW, Read RC, Varco RL, et al. Total body perfusion for open cardiotomy utilizing the bubble oxygenator: physiologic responses in man. J Thorac Surg 1956;32:591-603.

6. Zimmer HG. The Heart-lung machine was invented twice - the first time by Max von Frey. Clin Cardiol 2003;26:443-5.

7. https://www.eacts.org.

8. https://www.aats.org/aatsimis/AATSWeb.

9. Loop FD. Coronary artery surgery: the end of the beginning. Eur J Cardiothorac Surg 1998;14:554-71.

10. Lytle BW, Blackstone EH, Sabik JF, Houghtaling P, Loop FD, et al. The effect of bilateral internal thoracic artery grafting on survival during 20 postoperative years. Ann Thorac Surg 2004;78:2005-12.

11. Wilhelm MJ. Long-term outcome following heart transplantation: current perspective. J Thorac Dis 2015;7:549-51.

12. d'Udekem Y, Galati JC, Rolley GJ, Konstantinov IE, Weintraub RG, et al. Low risk of pulmonary valve implantation after a policy of transatrial repair of tetralogy of fallot delayed beyond the neonatal period: the melbourne experience over 25 years. $\mathrm{J}$ Am Coll Cardiol 2014;63:563-8.

13. Suri RM, Clavel MA, Schaff HV, Michelena HI, Huebner M, et al. effect of recurrent mitral regurgitation following degenerative mitral valve repair: long-term analysis of competing outcomes. J Am Coll Cardiol 2016;67:488-98.

14. Head SJ, Davierwala PM, Serruys PW, Redwood SR, Colombo A, et al. Coronary artery bypass grafting vs. percutaneous coronary intervention for patients with three-vessel disease: final five-year follow-up of the SYNTAX trial. Eur Heart J 2014;35:2821-30.

15. Quintana E, Suri RM, Thalji NM, Daly RC, Dearani JA, et al. Left ventricular dysfunction after mitral valve repair--the fallacy of "normal" preoperative myocardial function. J Thorac Cardiovasc Surg 2014;148:2752-60.

16. Pettersson GB, Hussain ST, Shrestha NK, Gordon S, Fraser TG, et al. Infective endocarditis: an atlas of disease progression for describing, staging, coding, and understanding the pathology. J Thorac Cardiovasc Surg 2014;147:1142-9.e2.

17. Schneider U, Feldner SK, Hofmann C, Schöpe J, Wagenpfeil S, et al. Two decades of experience with root remodeling and valve repair for bicuspid aortic valves. J Thorac Cardiovasc Surg 2017;153:S65-71.

18. Mestres CA, Bartel T, Sorgente A, Müller S, Gruner C, et al. Hypertrophic obstructive cardiomyopathy: what, when, why, for whom? Eur J Cardiothorac Surg 2018;53:700-7.

19. Czerny M, Schmidli J, Adler S, van den Berg JC, Bertoglio L, et al. Current options and recommendations for the treatment of thoracic aortic pathologies involving the aortic arch: an expert consensus document of the European Association for Cardio-Thoracic surgery (EACTS) and the European Society for Vascular Surgery (ESVS). Eur J Cardiothorac Surg 2019;55:133-62.

20. Säuberli H, Schriber K, Babotani I, Meier W, Senning A. Heart pacemaker--indications and results in 257 patients. Schweiz Rundsch Med Prax 1972;61:1354-9.

21. Leclercq JF, Menasché P, Laborde F, Coumel P, Piwnica A, et al. Clinical use of automatic implantable defibrillators. Eur Heart J 1987;8 Suppl D:143-7.

22. Banay GL. An introduction to medical terminology I. Greek and Latin derivations. Bull Med Libr Assoc 1948;36:1-27.

23. On the origin of species by means of natural selection, or the preservation of favoured races in the struggle for life. Br Foreign Med Chir Rev 1860;25:367-404.

24. Wan S, LeClerc JL, Antoine M, DeSmet JM, Yim AP, et al. Heparin-coated circuits reduce myocardial injury in heart or heart-lung transplantation: a prospective, randomized study. Ann Thorac Surg 1999;68:1230-5.

25. Tabesh H, Amoabediny G, Poorkhalil A, Khachab A, Kashefi A, et al. A theoretical model for evaluation of the design of a hollow-fiber membrane oxygenator. J Artif Organs 2012;15:347-56.

26. Gunaydin S, Modine T, Sari T, Zorlutuna Y, Gourlay T. Clinical efficacy of two-phase leukocyte filtration in high-risk patients 
undergoing coronary revascularization with cardiopulmonary bypass. J Extra Corpor Technol 2009;41:149-56.

27. Jabur GN, Sidhu K, Willcox TW, Mitchell SJ. Clinical evaluation of emboli removal by integrated versus non-integrated arterial filters in new generation oxygenators. Perfusion 2016;31:409-17.

28. Kühne LU, Binczyk R, Rieß FC. Comparison of intraoperative versus intraoperative plus postoperative hemoadsorption therapy in cardiac surgery patients with endocarditis. Int J Artif Organs 2019;42:194-200.

29. Hydra Greek Mythology. Available from: https://www.britannica.com/topic/Hydra-Greek-mythology. [Last accessed on 13 Nov 2019]

30. De Paulis R. EACTS News, April 2019. www.eacts.org

31. Perry JC. Roentgen rays-their application to medicine and surgery. Am J Dent Sci 1896;30:307-16.

32. Moniz E. Scientific raisins from 125 years SMW (Swiss Medical Weekly). Clinical and physiological results of cerebral angiography. 1935. Schweiz Med Wochenschr 1995;125:1503-7.

33. Cid dos Santos J. The diagnosis and treatment of vascular obstruction. Gaz Med Port 1948;1:631-43.

34. Edler I, Hertz CH. The use of ultrasonic reflectoscope for the continuous recording of the movements of heart walls. 1954. Clin Physiol Funct Imaging 2004;24:118-36.

35. Hatle L, Brubakk A, Tromsdal A, Angelsen B. Noninvasive assessment of pressure drop in mitral stenosis by Doppler ultrasound. Br Heart J 1978;40:131-40.

36. Hatle L. Introduction to Doppler echocardiography. Acta Paediatr Scand Suppl 1986;329:7-9.

37. Frazin L, Talano JV, Stephanides L, Loeb HS, Kopel L, et al. Esophageal echocardiography. Circulation 1976;54:102-8.

38. Matsumoto M, Inoue M, Tamura S, Tanaka K, Abe H. Three-dimensional echocardiography for spatial visualization and volume calculation of cardiac structures. J Clin Ultrasound 1981;9:157-65.

39. Vegas A, Meineri M. Three-dimensional transesophageal echocardiography is a major advance for intraoperative clinical management of patients undergoing cardiac surgery: a core review. Anesth Analg 2010;110:1548-73.

40. Hounsfield GN. Historical notes on computerized axial tomography. J Can Assoc Radiol 1976;27:135-42.

41. Damadian R. Tumor detection by nuclear magnetic resonance. Science 1971;171:1151-3.

42. Ghekiere O, Salgado R, Buls N, Leiner T, Mancini I, et al. Image quality in coronary CT angiography: challenges and technical solutions. Br J Radiol 2017;90:20160567.

43. Coughlan JJ, MacDonnell C, Arnous S, Kiernan TJ. Fractional flow reserve in 2017: current data and everyday practice. Expert Rev Cardiovasc Ther 2017;15:457-72.

44. Javadi M, Mahesh M, McBride G, Voicu C, Epley W, et al. Lowering radiation dose for integrated assessment of coronary morphology and physiology: first experience with step-and-shoot CT angiography in a rubidium 82 PET-CT protocol. J Nucl Cardiol 2008;15:783-90.

45. Pozzoli A, Maisano F, Kuwata S, Guidotti A, Plass A, et al. Fluoroscopic anatomy of the tricuspid valve: implications for transcatheter procedures. Int J Cardiol 2017;244:119-20.

46. Naoum C, Blanke P, Cavalcante JL, Leipsic J. Cardiac computed tomography and magnetic resonance imaging in the evaluation of mitral and tricuspid valve disease: implications for transcatheter interventions. Circ Cardiovasc Imaging 2017;10:e005331.

47. Pozzoli A, Zuber M, Taramasso M, Kuwata S, Maisano F. 3D echo-fluoro fusion imaging to guide Cardioband transcatheter mitral annuloplasty. Eur Heart J Cardiovasc Imaging 2018;19:827.

48. Di Carli MF, Geva T, Davidoff R. The future of cardiovascular imaging. Circulation 2016;133:2640-61.

49. Cribier A, Eltchaninoff H, Bash A, Borenstein N, Tron C, et al. Percutaneous transcatheter implantation of an aortic valve prosthesis for calcific aortic stenosis:first human case description. Circulation 2002;106:3006-8.

50. DeMaria AN. Structural heart disease? J Am Coll Cardiol 2014;63:603-4.

51. Mack MJ, Leon MB, Thourani VH, Makkar R, Kodali SK, et al. Transcatheter aortic-valve replacement with a balloon-expandable valve in low-risk patients. N Engl J Med 2019;380:1695-705.

52. Tenti E, Simonetti G, Bochicchio MT, Martinelli G. Main changes in European Clinical Trials Regulation (No 536/2014). Contemp Clini Trials Commun 2018;11:99-101.

53. Ailawadi G, Lim DS, Mack MJ, Trento A, Kar S, et al. One-year outcomes after MitraClip for functional mitral regurgitation. Circulation 2019;139:37-47.

54. Buckberg GD, Weisfeldt ML, Ballester M, Beyar R, Burkhoff D, et al. Left ventricular form and function: scientific priorities and strategic planning for development of new views of disease. Circulation 2004;110:e333-6.

55. Velasco-Hogan A, Deheyn DD, Koch M, Nothdurft B, Arzt E, et al. On the nature of the transparent teeth of the deep-sea Dragonfish, Aristostomias scintillans. Matter 2019; doi: 10.1016/j.matt.2019.05.010.

56. Victor S, Nayak VM. Evolutionary anticipation of the human heart. Ann R Coll Surg Engl 2000;82:297-302.

57. LEXICO. Available from: https://en.oxforddictionaries.com/definition/intellect. [Last accessed on 13 Nov 2019]

58. LEXICO. Available from: https://www.lexico.com/en/definition/frontier. [Last accessed on 13 Nov 2019] 